\title{
PARTICIPACIÓN EN FOROS ELECTRÓNICOS: DIALOGANDO CON UN DEFENSOR DEL ANTITRINITARISMO
}

\author{
Montero Guerrero, Rubén \\ Universidad Peruana Unión \\ rubenm32@yahoo.com
}

Fecha de recepción: Julio 2013

Fecha de aceptación y versión final: Noviembre 2013

El siguiente reporte de caso, está referido al contacto que el autor tuvo con la página Arquivos X da IASD producto de un intercambio epistolar con un miembro de la Iglesia Adventista del $7^{\circ}$ Día que había aceptado los argumentos antitrinitarios. Se presenta una breve descripción del debate que se mantuvo por emails y las respuestas a las principales objeciones levantadas en esta página, especialmente a dos argumentos básicos que son presentados: La creencia antitrinitaria que tenían importantes pioneros del adventismo y la supuesta manipulación de documentos para favorecer al trinitarianismo en la IASD. Se exponen también las razones que el autor tuvo para participar en este debate y las conclusiones que contienen una breve reflexión acerca de cómo enfrentar los múltiples ataques que recibe la iglesia a través de internet. Finalmente, se deja al lector una serie de preguntas que no tienen respuesta en la página Arquivos X da IASD, y que podrían ser útiles en el diálogo con defensores del antitrinitarianismo.

Palabras clave: Trinidad, Dios el Padre, Dios el Hijo, Dios el Espíritu Santo, Apologética. 


\section{INVOLVEMENT OF AN ELECONTRONIC FORUM: ARGUMENTING WITH A ANTITRINITARIAN}

The following report refers to the contact the author had with the Arquivos $\chi$ da IASD page, product of a epistolary exchange with a member of the Seventh-Day Adventist that had accepted the antitrinitarian arguments. A brief description of the debate is presented, (which was held via e-mails), including the answers to the primary objections given in this page, especially two basic arguments that are presented in the following way: The antitrinitarian belief that important Adventist pioneers shared, and the proposed manipulation of documents that favored trinitarianism in the SDA church. The reasons the author had for participating in this debate and the conclusions that contain a brief reflection about how to face the constant attacks the church receives online were presented as well. Finally, the reader is given a series of questions that have no answer in the Arquivos X da IASD page, and that could be useful in dialoging with antitrinatarians.

Keywords: Trinity, The Father, the Son, and the Holy Spirit, Apologetics. 


\section{Introducción}

Eran las últimas semanas de nuestra estancia en un distrito misionero, me hicieron saber que Samuel ${ }^{1}$ uno de los más queridos líderes de la iglesia estaba teniendo contacto con grupos antitrinitarios y que había empezado a difundir ideas contrarias a la doctrina adventista. Cuando fui a visitarlo, Samuel y su esposa nos abrieron las puertas de su hogar muy gentilmente, como siempre lo habían hecho, y tuvimos una corta conversación en la que no llegamos a tratar en profundidad el tema del antitrinitarianismo. Quedamos en que conversaríamos en profundidad en una siguiente visita.

Pocos días después tuvimos un segundo encuentro, donde

1 Se escribe este artículo con el consentimiento expreso de Samuel Wackimaker, quien pidió que los lectores del mismo tengan acceso al debate en su totalidad, y ya que es imposible colocar el íntegro del debate en este artículo, pues contiene 56 páginas, se ha colocado el documento completo en internet. Los interesados pueden hallarlo en el siguiente link: http://es.scribd.com/doc/174684394/ Debate-Con-Antitrinitarios hablamos con mayor tiempo, momento en el que presentó los argumentos a los que llamó sus "nuevas convicciones personales". Se podía percibir que Samuel no quería comprender mejor la doctrina de la Trinidad ya que no hacía preguntas y sólo compartía sus certezas, sus "nuevos principios". A esas alturas, ya la iglesia había determinado que Samuel no debería predicar, ni ser maestro de Escuela Sabática, ni ser líder de grupo pequeño. Estas eran medidas preventivas que la iglesia había tomado mientras se intentaba hacer un trabajo espiritual con él.

Unos pocos días después se reunió toda la iglesia, pues había muchas preguntas que los hermanos se hacían en relación con la doctrina de la Trinidad, y es que Samuel había visitado a las familias de la iglesia con el propósito de compartir sus nuevas convicciones antitrinitarias. En esta reunión, presenté los argumentos bíblicos y del Espíritu de Profecía sobre la Trinidad. La iglesia quedó satisfecha con la fundamentación de la doctrina 
adventista y ningún miembro se unió a la corriente del antitrinitarianismo. Algunos días después me trasladé a mi nuevo campo misionero en la ciudad de Belo Horizonte. Perdí el contacto con Samuel por varios meses hasta que me envió un email con citas de Elena de White que, supuestamente, sustentaban una posición contraria a la doctrina adventista de la Trinidad. Respondí con algunas citas claramente trinitarias de Elena de White, y así, sin proponérmelo me vi envuelto en un debate sobre la Trinidad que se prolongó a través de catorce emails. Prácticamente desde que el debate empezó, Samuel envió nuestros emails a varias personas, lo que me colocaba en una situación de mayor responsabilidad, porque cualquier debilidad argumentativa de mi parte podría ser usada por los antitrinitarios como una prueba a favor de sus ideas teológicas.

En su segundo email, Samuel me escribió un mensaje que decía "saque usted sus propias conclusiones", y contenía un vín- culo a una página en internet, escrita en portugués y titulada Arquivo $\chi$ da IASD. Esta página de internet se presentaba como una que investiga algunos supuestos aspectos oscuros de la IASD. En realidad, este artículo resultaría insuficiente para responder a todos los infundios presentados en esa web. La tesis central de esta facción antitrinitaria es que la doctrina de la Trinidad no es bíblica y que fue introducida en la IASD como una concesión por parte de líderes de iglesia que, supuestamente, estarían más interesados en congraciarse con los evangélicos que en mantener la pureza original de la doctrina adventista.

Para probar que este cambio efectivamente sucedió, básicamente utilizan como argumentos las creencias antitrinitarias de importantes pioneros de la IASD y supuestas manipulaciones en los documentos de la iglesia y en los escritos de Elena G. de White para introducir la Trinidad en la iglesia adventista. 
Las creencias antitrinitarias de importantes pioneros de la IASD

Uno de los principales argumentos con los que se intenta demostrar que los líderes de la iglesia cambiaron una doctrina básica de nuestra fe, es recurrir a varias declaraciones de algunos de los más importantes pioneros del adventismo. Algunas de las declaraciones usadas en Arquivos $X$ da IASD, dicen pertenecer a Jaime White y otros autores, ${ }^{2}$ al-
La gran falla de la Reforma fue que los reformadores dejaron de

2 Los párrafos están en la página de Arquivos $X$ da IASD originalmente en portugués, la traducción al español ha sido realizada por el autor. Se debe señalar que no se hace fácil para el investigador confirmar las fuentes señaladas en Arquivos $X$ da IASD, ejemplo de ello es la mención de la Advent Review en los siguientes pies de página, pues ella no forma parte de la base de datos de revistas y otras publicaciones oficiales de la Iglesia Adventista del $7^{\circ}$ Día y la Review and Herald de 1856, sin título ni número ya que en ese año se publicaron dos volúmenes y un total de 47 números distribuidos en tres volúmenes. Cf. http:// docs.adventistarchives.org/ reformar. Si hubiesen continuado, no habrían dejado vestigios del papado, tales como la doctrina de la inmortalidad natural, el bautismo por aspersión, la trinidad, la observancia del domingo, y la iglesia estaría ahora libre de errores escriturísticos. ${ }^{3}$

Que una persona sea tres personas, y que tres personas sean una sola persona, es una doctrina que nosotros declaramos ser una doctrina contraria a la razón y al sentido común. ${ }^{4}$

Estaba en lo correcto cuando dije que la doctrina de la Trinidad degrada la expiación trayendo el sacrificio, la sangre por la que somos comprados, para un nivel inferior de compromiso. ${ }^{5}$

Asimismo, se presenta esta declaración de J.N. Lougborough:

Esta doctrina de la Trinidad fue introducida en la iglesia en la misma época que la adoración

3 Review and Herald, 1856. Jaime White. [respecto al formato de esta referencia bibliográfica véase la nota 2 de pie de página]

4 Advent Review, 6 de Julio de 1869. Jaime White. [respecto al formato de esta referencia bibliográfica véase la nota 2 de pie de página]

5 Advent Review, 10 de Noviembre 1863. Jaime White. [respecto al formato de esta referencia bibliográfica véase la nota 2 de pie de página] 
de imágenes y la observancia del domingo, y no es más que la doctrina de los persas remodelada. ${ }^{6}$ J. N. Andrews también es mencionado:

La doctrina de la Trinidad fue establecida en la iglesia por el concilio de Nicea el 325 d.C. Esa doctrina destruye la personalidad de Dios y su Hijo Jesucristo, nuestro Señor. La manera infame cómo fue impuesta en la iglesia aparece en las páginas de la historia eclesiástica, que provoca en los que creen en esa doctrina enrojecer de vergüenza. ${ }^{7}$

Otro insigne pionero, Uriah Smith, también aparece entre los pioneros mencionados. Se toma un párrafo de un artículo suyo publicado en la Review and Herald:

Pero con respecto al Espíritu, la Biblia usa expresiones que no pueden estar en armonía con la idea que es una persona igual

6 Advent Review, 5 de Noviembre de 1861. J.N. Lougborough. [respecto al formato de esta referencia bibliográfica véase la nota 2 de pie de página]

7 Advent Review, 6 de Marzo de 1855. J.N. Andrews. [respecto al formato de esta referencia bibliográfica véase la nota 2 de pie de página] al Padre y al Hijo. Al contrario muestra que es una influencia divina de ambos, el medio por el cual se hacen representar y por el cual se manifiesta el poder a través de todo el universo, cuando no están personalmente presentes"

Juntamente con esas declaraciones, se colocan declaraciones de Elena de White elogiando a estos pioneros con ideas antitrinitarias, y se argumenta que Elena de White estaría también apoyando la doctrina antitrinitaria que ellos defendían. Es decir, toda la argumentación se reduce a un silogismo: "Al-

8 La traducción es del autor, el texto en portugués tal como aparece en Arquivos $X$ da IASD es el siguiente: "Mas com respeito ao Espírito, a Bíblia usa expressões que não podem se harmonizar com a idéia que é uma pessoa igual ao Pai e ao Filho. Ao contrário mostra que é uma divina influência de ambos; o meio pelo qual se fazem representar e pelo qual se manifesta o poder através de todo o universo, quando não estão pessoalmente presentes." Urias Smith, "In the Question Chair", Review and Herald, LXVII (28/10/1890), 664. http://www.arquivoxiasd.com/defesa. htm. [respecto al formato de esta referencia bibliográfica véase la nota 2 de pie de página] 
gunos pioneros de la IASD de vida ejemplar y conducta cristiana no creían en la Trinidad", "Elena de White elogió la vida ejemplar y conducta cristiana de varios de ellos", entonces "Elena de White estaba de acuerdo con las ideas antitrinitarias de estos pioneros". Asimismo, se arguye que las doctrinas adventistas estaban claramente establecidas desde los inicios del movimiento adventista. Para sustentar esta posición recurren a citas de Elena de White similares a esta:

$\mathrm{Ni}$ una sola palabra ha sido 100 cambiada o anulada. Lo que el Espíritu Santo testificó que era la verdad, después de transcurrida la fecha del gran chasco, es el fundamento sólido de la verdad. Fueron revelados los pilares de la verdad y aceptamos los principios fundamentales que han hecho de nosotros lo que somos: Adventistas del Séptimo Día, los que guardan los mandamientos de Dios y tienen la fe de Jesús. ${ }^{9}$

9 Por el contexto, esta cita revela la confianza que tenía Elena de White en relación al mensaje de 1844 y el mensaje del santuario. Como veremos más adelante, no se puede interpretar esta frase como que ya

\section{Respuesta}

Al elaborar esta argumentación, los autores de Arquivos $\chi d a$ IASD incurren en un tipo de falacia llamada argumentum ad verecundiam, que consiste en afirmar que algo es verdadero porque alguna persona con cierta autoridad lo afirma. Su afirmación puede ser escrita así: "la doctrina de la Trinidad no es verdadera porque los pioneros no creyeron en ella". De una forma sutil, los autores de esta página tratan de llevar al lector por una serie de declaraciones de los pioneros haciéndoles perder de vista el punto esencial, a saber la autoridad sobre la cual descansa la doctrina adventista.

\section{La Biblia como norma de fe y doctrina}

Es un hecho probado que algunos de los más prominentes pioneros de nuestra iglesia no no habría nuevas verdades que el pueblo iba a descubrir en la Palabra de Dios. Elena G. de White, Alza tus ojos (Buenos Aires: Asociación Casa Editora Sudamericana, 1988), 350. 
solo no creían en la Trinidad, sino que la calificaron como un doctrina que provenía del catolicismo romano. El punto más importante que se debe considerar es la autoridad que los pioneros tienen en materia de doctrina. Los adventistas del séptimo día nunca han creído que los pioneros hayan tenido alguna autoridad en relación con el fundamento doctrinal y teológico del adventismo. Como herederos de la reforma, sostenemos la plena vigencia del principio de Sola Scriptura, y creemos que la Biblia es la única fuente de verdad y doctrina. Nuestros pioneros fueron hombres y mujeres, de fe admirable, pero en relación con las verdades de la Palabra de Dios no tienen ninguna superioridad sobre nosotros. La Biblia es la Palabra de Dios, no los escritos de Uriah Smith o Jaime White. El punto central en relación con el tema de la Trinidad, o cualquier otro tema, creencia o doctrina; no es qué es lo que creían los pioneros, sino qué es lo que la Biblia dice al respecto. Nuestros pioneros también estaban creciendo en el conocimiento de las verdades bíblicas. La pregunta fundamental es ¿Enseña la Biblia la doctrina de la Trinidad? Mi respuesta, después de un estudio personal de la Sagrada Escritura es SÍ, la Trinidad es una verdad bíblica, ${ }^{10}$ y la Iglesia adventista, al tenerla como un fundamento de fe y enseñarla, está en lo correcto.

Cualquier intento de probar una doctrina mediante los escritos o dichos de los pioneros socava la autoridad de la Palabra de Dios, y resulta inaceptable para un verdadero adventista del séptimo día. Sería actuar de modo equivalente al de la iglesia católica que acepta el magisterio de la Iglesia y la voz de la autoridad papal y conciliar como de igual autoridad que la propia Palabra de Dios. Asimismo, tal postura revela un pobre conocimien-

10 Este artículo no contiene una argumentación bíblica sobre la Trinidad, sin embargo, en el siguiente vínculo http:// es.scribd.com/doc/174684394/DebateCon-Antitrinitarios el lector podrá ver el desarrollo total del debate, que contiene una breve exposición de los textos bíblicos que prueban que la Trinidad es una enseñanza bíblica. 
to del carácter progresivo de la comprensión de las verdades bíblicas en el pueblo de Dios.

\section{El carácter progresivo del desarrollo doctrinal de la IASD}

Los autores de la web Arquivos $\chi$ da IASD sostienen que, en sus primeros años, el adventismo ya tenía una plena comprensión de las doctrinas y enseñanzas bíblicas, y que al apartarse de las doctrinas de los pioneros, incurre en apostasía. Como ve-

102 remos a continuación, el establecimiento de la doctrina adventista tal como hoy la conocemos, fue un proceso que duró varios años, claramente evidenciada en la siguiente cronología:

1. En 1844, Elena de White guardaba el domingo, y lo guardó por aproximadamente tres años más.

2. En 1855 , los adventistas comenzaron a guardar el sábado a partir de la puesta del sol del día viernes, antes lo hacían desde las seis de la tarde.

3. En 1863, los adventistas aceptan las verdades referentes a la reforma de salud. Antes, muchos de ellos, incluso, comían carne de cerdo.

4. En 1888 , la Iglesia entra en un debate teológico que la lleva a la aceptación plena de la justificación por la fe.

5. En 1898, con la publicación del Deseado de todas las gentes, Elena G. de White, que nunca antes se había manifestado en contra de la doctrina de la Trinidad, presenta los primeros pasos en una dirección abiertamente trinitaria. Esta posición marca una ruptura respecto a la ambigüedad con la que ella había tratado el tema anteriormente, y marca el inicio de una comprensión más cabal respecto a la Deidad en el seno de la Iglesia Adventista del $7^{\circ}$ Día. 
Es verdad que hay citas de Elena de White que podrían dar a entender que la doctrina ya se había establecido firmemente en los primeros años, pero un análisis de esas citas nos demuestra que ella se refería a las llamadas doctrinas distintivas de la Iglesia que eran llamadas de verdad presente, tales como la segunda venida literal de Cristo, el santuario y el juicio. Por otro lado, ella refiere en múltiples oportunidades el carácter progresivo del descubrimiento de las verdades bíblicas. Algunas citas que apoyan esta afirmación son,

Tenemos que aprender muchas lecciones y muchas más son las que hemos de aprender. Únicamente Dios y el cielo son infalibles. Quienes se figuran que nunca habrán de renunciar a una idea con la que estén encariñados, ni que tendrán ocasión de mudar de criterio, quedarán desengañados. Mientras nos aferramos con determinada persistencia a nuestras propias ideas y opiniones, no podremos tener la unidad por la cual oraba Cristo.

Cuando cualquier hermano reciba nueva luz sobre las Escrituras, debe exponer francamente su parecer, y cada predicador debe escudriñar las Escrituras ingenuamente para ver si los puntos expuestos pueden fundamentarse en la inspirada Palabra. "El siervo del Señor no debe ser litigioso, sino manso para con todos, apto para enseñar, sufrido; que con mansedumbre corrija a los que se oponen; asi quizá Dios les dé que se arrepientan para conocer la verdad". 2 Timoteo 2: 24, 25.11

Mi labor en el campo se ha desarrollado desde 1845. Desde entonces he trabajado con la pluma y la voz. La luz que he recibido ha aumentado a medida que la he impartido. Tengo mucho más sobre pasajes del Antiguo y del Nuevo Testamento, que presentaré a la gente. ${ }^{12}$

La historia de la Iglesia nos muestra de modo contundente que el descubrimiento de las nobles verdades que son el cimiento doctrinario de la IASD ha sido un proceso de varios años.

11 Elena G. de White, Testimonios selectos, 5 vols. (Buenos Aires: Casa Editora Sudamericana, 1942), 1: 200. La cursiva es nuestra.

12 Elena G. de White, Mensajes selectos, 3 vols. (Mountain View, CA: Pacific Press Publishing Association, 1966), 3: 100-01. La cursiva es nuestra. 
Un proceso que no ha estado libre de posiciones encontradas ni de encendidas polémicas. Sin embargo, si como miembros de la Iglesia remanente, nos enfrascamos en temas que ya fueron resueltos en tiempos pasados, simplemente estamos desconociendo la guía divina, porque ha sido el Espíritu Santo quien ha guiado el establecimiento del cuerpo doctrinal de la Iglesia.

Por otro lado, la web Arquivos $X \mathrm{da}$ IASD, sostienen que los elogios que hizo Elena de White a algunos de los pioneros, son 104 pruebas de que ella también concordaba con sus posiciones antitrinitarias. Este es un argumento del todo efectista, ya que, como establecimos anteriormente, solo la Biblia es norma de fe y doctrina. Por otro lado, las palabras elogiosas que Elena de White expresó sobre algunos de estos pioneros no son suficientes para afirmar que ella aceptaba plenamente todo su pensamiento teológico. Hay que recordar que ella también escribió muchos párrafos elogiando la fe y la va- lentía de Martín Lutero, ${ }^{13}$ pero eso no significa que concordaba plenamente con la toda la teología de Lutero.

\section{Elena G. de White y la doctrina adventista}

Es necesario revisar el rol de Elena G. de White en relación con el establecimiento del cuerpo doctrinal de la Iglesia Adventista del $7^{\circ}$ Día, al respecto ella misma dijo:

Vez tras vez aquellos hermanos se reunían para estudiar la Biblia, a fin de descubrir su significado y a fin de estar preparados para predicarlo con poder. Cuando en su estudio llegaban al punto de de-

13 En El conflicto de los siglos, Elena de White escribió las siguientes palabras: "El más distinguido de todos los que fueron llamados a guiar a la iglesia de las tinieblas del papado a la luz de una fe más pura, fue Martín Lutero. Celoso, ardiente y abnegado, sin más temor que el temor de Dios y sin reconocer otro fundamento de la fe religiosa que el de las Santas Escrituras fue Lutero, el hombre de su época. Por su medio realizó Dios una gran obra para reformar a la iglesia e iluminar al mundo". Elena G. de White, El conflicto de los siglos (Bogotá: Asociacion Publicadora Interamericana, 2007), 129. 
cir: 'Nada más podemos hacer,' el Espíritu del Señor descendía sobre mí; era arrebatada en visión y se me daba una clara explicación de los pasajes que habíamos estado estudiando, y también instrucciones acerca de cómo habíamos de trabajar y enseñar eficazmente. Así se nos daba luz que nos ayudaba a comprender las escrituras referentes a Cristo, su misión y su sacerdocio. ${ }^{14}$

Este testimonio resulta esclarecedor sobre la manera en que los adventistas iban descubriendo los puntos principales de las doctrinas bíblicas. Ellas fueron el producto de un estudio diligente y profundo de la Palabra de Dios. Las doctrinas no salieron de la cabeza de algún pionero, por el contrario, ellos buscaban la verdad bíblica como se busca un tesoro inestimable. Elena de White, en esta etapa, frecuentemente no entendía bien los asuntos que se estaban tratando, en realidad ella tuvo una mayor comprensión de las verdades bíblicas solo cuando es-

14 Elena G. de White, Primeros escritos (Mountain View, CA: Pacific Press Publishing Association, 1962), XXI, XXII. tas ya estuvieron establecidas. ${ }^{15}$ Las visiones que ella recibía señalaban el camino a seguir en el estudio y la enseñanza de la Palabra de Dios, pero no sustituían el estudio de la Palabra de Dios. Los testimonios no han traído nuevas verdades a la Iglesia, ellas fueron establecidas para consolar al pueblo de Dios y para corregir a quienes se apartan de la verdad bíblica. Este énfasis en la Biblia como fundamento doctrinal se puede ver con claridad en la siguiente declaración:

Recomiendo al amable lector la Palabra de Dios como regla de fe y práctica. Por esa Palabra hemos

15 En relación con su comprensión de los asuntos teológicos estudiados, Elena de White comentó: "Durante todo ese tiempo yo no podía entender el razonamiento de los hermanos. Mi mente estaba, por así decirlo, trabada, y no podía comprender las escrituras que estábamos estudiando. Esto constituía uno de los mayores pesares de mi vida. Estuve en esa condición hasta que todos los puntos principales de nuestra fe se aclararon para nuestra mente, en armonía con la Palabra de Dios. Los hermanos sabían que cuando yo no estaba en visión no podía comprender esos asuntos, y aceptaban las revelaciones dadas como luz que provenía directamente del cielo". White, Mensajes selectos, 1: 241-42. 
de ser juzgados. En ella Dios ha prometido dar visiones en los "postreros días", no para tener una nueva norma de fe, sino para consolar a su pueblo y para corregir a los que se apartan de la verdad bíblica. Así obró Dios con Pedro cuando estaba por enviarlo a predicar a los gentiles. ${ }^{16}$

Este papel de orientación hacia la verdad y corrección de errores doctrinales, también se aprecia en relación con el establecimiento de la Trinidad en la IASD. Se puede advertir claramente en los escritos de

106 Elena de White una progresión, que va desde una relativa ambigüedad para tratar el tema hacia una definición a favor de la Trinidad. Un aspecto muy significativo es que, a pesar de la tendencia claramente antitrinitaria de varios de los pioneros, Elena de White nunca se pronunció en contra de la Trinidad. No existe ninguna declaración en la que ella apoye el antitrinitarianismo de algunos de sus contemporáneos. Parece ser, que para ella era un

16 Ibíd., 3: 33. tema que se iría resolviendo a medida que haya más luz al respecto. Sus escritos iniciales, que no contienen definiciones a favor o en contra de la Trinidad, podían ser aceptados tanto por trinitarios como por antitrinitarios. ${ }^{17}$ A partir de la publicación de la primera edición del Deseado de todas las gentes en 1898, es que Elena de White sostiene una posición más definidamente trinitaria. Puede verse claramente cómo el Espíritu de Profecía cumplió un importante papel en la aceptación de la doctrina de la Trinidad en el seno de la Iglesia adventista. Describiendo este proceso, Jerry Moon señala: "Bloque por

17 Hay que recordar que entre los primeros adventistas habían personas que venían de diferentes denominaciones cristianas. Había metodistas, bautistas, presbiterianos, luteranos, etc. Con esta conformación tan variada es lógico que exista un gran potencial para interminables conflictos teológicos. Es evidente que la creencia que los unía era la segunda venida literal de Cristo, según la interpretación de Miller. En estas circunstancias, no es de extrañar que el proceso de conformación de un sistema coherente de doctrinas no estaría exento de conflictos y momentos dolorosos. 
bloque conceptual (tal vez sin estar plenamente consciente), lenta pero firmemente, ella estaba demoliendo la estructura de la opinión antitrinitaria y construyendo un punto de vista trinitario". ${ }^{18}$

\section{Supuesta manipulación de documentos}

La segunda línea de argumentación que presenta Arquivos $\chi$ da IASD tiene que ver con acusaciones sobre manipulación de documentos. Estas supuestas manipulaciones tendrían el propósito de ocultar la creencia antitrinitaria de la Iglesia adventista auroral, y dar paso a un cambio doctrinal, un cambio que llevase a la aceptación de la doctrina de la Trinidad en la Iglesia. Como objetivo central, ese cambio pretendía hacer que la Iglesia adventista tuviese un perfil doctrinal más aceptable al mundo evangélico. En este estudio presentaremos

18 Jerry Moon, "Ellen G. White e a comprenssao da Trindade", Parousia 5 n ${ }^{\circ} 1$ (1 semestre 2006): 11-25. tres ejemplos que menciona Arquivos $X$ da IASD: los cambios introducidos en el Yearbook a lo largo de los años, el vocablo Trinidad en las traducciones al portugués de los escritos de Elena de White, y la supuesta manipulación de algunos manuscritos de Elena de White.

\section{Cambios en el Yearbook}

El primer ejemplo que se presenta se relaciona con los cambios en la lista de Principios Fundamentales realizados en el Yearbook. Se resalta que en las primeras ediciones, el Yearbook tenía una declaración de Principios Fundamentales sin matices trinitarios, ${ }^{19}$ y se afirma, que con el transcurrir del tiempo, esas declaraciones fueron dando paso a otras, más

19 Según se presenta en Arquivos da $I A S D$, en las primeras ediciones del Yearbook, se presentaba la creencia de Dios el Padre en primer lugar y luego, en segundo lugar, se presentaba la creencia en un Señor Jesucristo, el Hijo del Padre. No hay ninguna doctrina relativa al Espíritu Santo, y solo se le hace una breve mención como representante de Dios el Padre en el primer principio fundamental. 
acordes con la doctrina de la Trinidad y en detrimento de la creencia que tenía la Iglesia adventista en sus inicios. Finalmente, Arquivos $X$ da IASD, sostiene que en 1931 se habría consumado la apostasía cuando el Yearbook publica entre los principios fundamentales la siguiente declaración:

Que la Divinidad o Trinidad, consiste en el Padre Eterno, un Ser personal, espiritual, omnipotente, omnipresente, omnisciente, infinito en sabiduría y amor; el Señor Jesucristo, el Hijo del Padre Eterno, a través de quien todas las cosas fueron creadas y a través de quien la salvación de multitudes redimidas será cumplida; el Espíritu Santo, la tercera persona de la Divinidad, el gran poder regenerador en la obra de redención (S. Mat. 28:19). ${ }^{20}$

\section{Respuesta}

La declaración original de los principios fundamentales

20 Tomado de http://denepaz.es.tl/ historia-de-la-trinidad-en-la-iglesia-adventista.htm. [respecto al formato de esta referencia bibliográfica véase la nota 2 de pie de página] tal como aparece en el primer número del Yearbook en 1889 es la siguiente: "That there is one God, a personal, spiritual being, the creator of all things, omnipotent, omniscient, and eternal, infinity in wisdom, holiness, justice, goodness, truth and mercy; unchangeable, and every where present by his representative, the Holy Spirit". Traducido al español, el texto diría: "Que hay un Dios, un ser espiritual y personal, el creador de todas las cosas, omnipotente, omnisapiente y eternal, infinito en sabiduría, santidad, justicia, bondad, verdad y misericordia; inmutable, y presente en todo lugar a través de su representante, el Espíritu Santo".

Me gustaría hacer algunas preguntas sobre esta declaración: ¿Puede un adventista actual, un trinitario, aceptar esta declaración? ${ }^{21}$ La respuesta es sí. ¿Puede un adventista sentir que la enseñanza bíblica de la Trinidad es rechazada convincentemente en esta declaración? La

21 A la luz de nuestro estudio, adventista trinitario es un pleonasmo. 
respuesta es no. Como adventistas creemos que nuestro Dios es un ser personal, espiritual, y creador de todas las cosas. También creemos que Dios se hace presente a través de su representante, el Espíritu Santo. Creo que no hay razón para afirmar una escandalosa sustitución doctrinal. Por el contrario, esta declaración parece tener el concepto embrionario de la Trinidad, al colocar al Espíritu Santo así, con mayúsculas. Sin embargo, a la luz del proceso histórico de consolidación doctrinal del adventismo, creo que esta declaración es suficientemente ambigua como para permitir que las diversas corrientes comulguen en la misma declaración de principios fundamentales. El proceso de aceptación de la doctrina de la Trinidad empezará recién a partir de 1898 y sería apoyado por la propia Elena de White, a través de la publicación del Deseado de todas las gentes.

\section{La traducción de Trinidad en el portugués ${ }^{22}$}

Arquivos $\chi$ da IASD resalta el hecho que no existe la palabra Trinidad (Trinity en inglés) en ninguno de los escritos originales de Elena de White, y que hay una intención de fraude al traducir la palabra inglesa Godhead por la palabra portuguesa Trindade, ${ }^{23}$ en lugar de Divinda$d e^{24}$ o Deidade ${ }^{25}$ como correspondería.

\section{Respuesta}

Habría que recordarles a los escritores, moderadores y editores de Arquivos $\chi$ da IASD, que una traducción no es simplemente una trasposición de palabras de una lengua a otra. No traducimos solo palabras, sino que también traducimos

22 Este problema no se encuentra en las traducciones al español, sin embargo, me parece útil presentarlo a los lectores de habla española, para señalar las inconsistencias argumentativas de Arquivos $X \mathrm{da}$ IASD.

23 Trinidad en español

24 Divinidad en español

25 Deidad en español 
significados y referencias entre diversas culturas. La traducción no es, por lo tanto, una actividad puramente técnica y objetiva, sino que en esta la interpretación pasa a ser un elemento fundamental. Lo importante es que el traductor no realice una interpretación que distorsione el pensamiento del autor, su interpretación debe estar en línea con el pensamiento del autor. En otras palabras, en la traducción lo más importante no son solo las palabras, lo más importante son los pensamientos, las ideas

110 que serán transmitidas para el lector en otro idioma. Eso vale para todo tipo de traducción, incluyendo los escritos de Elena de White. Por tanto, lo más importante en la traducción no es si ella escribió una u otra palabra específica, en este caso Trinidad (Trindade en portugués), lo más importante es determinar si su pensamiento es o no trinitario, porque si su pensamiento era trinitario entonces no habría ningún error si el traductor usa la palabra Trinidad (Trindade en portugués) al traducir sus libros.
Si se busca en un programa informático de los escritos de Elena de White en portugués, se encontrará que efectivamente el término inglés Godhead ha sido traducido como Trindade en varios párrafos. ${ }^{26}$ Exactamente son trece las referencias en las que esto ocurre. Al excluir los títulos y las referencias repetidas, quedan seis para ser estudiadas, que de aceurdo a Arquivos X da IASD son los siguientes: ${ }^{27}$

1. Siendo participantes de la naturaleza divina, podemos permanecer puros, santos e incontaminados. La Trinidad (Trindade) no se tornó humana, y lo humano no fue deificado por la combinación de las dos naturalezas. ${ }^{28}$

2. Cristo envió su represen-

26 En portugués se traduce Godhead por Trindade en varios textos. En el caso de las traducciones al español es diferente, ningún libro de Elena de White traducido al español contiene la palabra Trinidad.

27 La traducción y las palabras entre paréntesis son nuestras.

28 Manuscrito 94, 1893. [respecto al formato de esta referencia bibliográfica, véase la nota 2 de pie de página] 
tante, la tercera persona de la Trinidad (Trindade), el Espíritu Santo. Nada podía superar ese don. ${ }^{29}$

3. Al pecado solo se podría resistir y vencer por medio de la poderosa operación de la tercera persona de la Trinidad (Trindade) ${ }^{30}$

4. Hay tres personas vivas pertenecientes a la Trinidad (Trindade) celestial; en el nombre de estos tres grandes poderes -el Padre, el Hijo y el Espíritu Santo ${ }^{31}$

5. El príncipe de la potestad del mal solo puede ser mantenido en sujeción por el poder de Dios en la tercera persona de la Trinidad (Trindade), el Espíritu Santo. ${ }^{32}$

29 Manuscrito 84, 1898. [respecto al formato de esta referencia bibliográfica véase la nota 2 de pie de página]

30 Desejado de Todas as Nações, 671. [respecto al formato de esta referencia bibliográfica, véase la nota 2 de pie de página]

31 Série B, N. ${ }^{\circ}$ 7, 62 e 63 . [respecto al formato de esta referencia bibliográfica, véase la nota 2 de pie de página]

32 Special Testimonies, Série A, N.
6. El mal se venía acumulando por siglos, y solo podría ser restringido y resistido por el poder eficaz del Espíritu Santo, la tercera persona de la Trinidad (Trindade). ${ }^{33}$

$\mathrm{Al}$ hacer una lectura simple de estos seis párrafos, se nota rápidamente que en cinco de ellos, el traductor no se equivocó al usar la palabra Trinidad (Trindade), ya que es la única conclusión obvia a la que conduce el contexto de la palabra. Es decir, si bien la traducción literal de Godhead debería ser Divinidad (Divindade) o Deidad (Deidade), el contexto es claramente trinitario, por tanto no hay ninguna intención de fraude al traducir la palabra inglesa como Trinidad (Trindade).

10, 37. [respecto al formato de esta referencia bibliográfica, véase la nota 2 de pie de página]

33 Testemunhos para Ministros e obreiros evangelicos, 392. [respecto al formato de esta referencia bibliográfica, véase la nota 2 de pie de página] 
Supuesta manipulación de los escritos de Elena de White $^{34}$

Arquivos $\chi$ da IASD, sostienen que los líderes la Iglesia adventista no dudaron en manipular algunos párrafos de los escritos de Elena de White para dar la impresión que ella apoya la doctrina de la Trinidad. Un ejemplo que presentan en la web es el siguiente:

En inglés fue publicado el siguiente párrafo: "There are three living persons of the heavenly trio; in the name of these three great powers - the Father, the Son, and the Holy Spirit..." 35 Sin embargo, el manuscrito original dice "There are (the) living three

34 El desarrollo de estas argumentaciones ha sido tomado de http://www. arquivoxiasd.com/pg671.htm [respecto al formato de esta referencia bibliográfica véase la nota 2 de pie de página]

35 En español, este párrafo se encuentra en el libro El evangelismo, y ha sido traducido de la siguiente manera: "Hay tres personas vivientes en el trío celestial; en el nombre de estos tres grandes poderes el Padre, el Hijo y el Espíritu Santo..." Elena G. de White, El evangelismo (Buenos Aires: Casa Editora Sudamericana, 1991), 446. persons (alities) of the heavenly trio...." ${ }^{36}$

Aquí está la prueba, dicen los antitrinitarios, de los cambios introducidos para favorecer la doctrina de la Trinidad en los escritos de Elena de White. Ellos arguyen que Elena de White escribió claramente en el original la palabra personalidades (personalities), y que cuando este párrafo fue publicado se hizo como personas (persons). Dicen ellos que hay una tremenda diferencia conceptual entre "personas" y "personalidades", y explican que personalidad se refiere a cualidades y carácter. Esta pequeña diferencia entre el original y lo que finalmente fue publicado no es algo trivial para los autores de Arquivos X, ellos creen que al cambiar el texto de personas a personalidades se comprueba el intento de manipulación de los escritos de Elena de White, para ellos se trata de un intento de fraude perpetrado con el propósito de hacer ver

36 Las palabras entre paréntesis son las correcciones de Elena de White a su propio manuscrito. 
que Elena de White tenía un pensamiento trinitario.

\section{Respuesta}

Un artículo de Tim Poirier ${ }^{37}$ demuestra de modo conclusivo que el párrafo en cuestión es de autoría de Elena de White. El análisis de Poirier incluye los siguientes elementos:

1. El procedimiento usado por Elena de White para la publicación de sus libros incluía, por lo general, los siguientes pasos:

a. Elena de White escribía el original a mano,

b. Su secretaria personal dactilografiaba el manuscrito original,

c. Elena de White revisaba el trabajo de la secretaria y, si veía necesario, realizaba algunas correcciones,

d. Los escritos dactilogra-

37 Tim Poirier, "As declarações trinitarianas de Ellen G. White: o que ela realmente escreveu?" Parousia $5 \mathrm{n}^{\circ} 1\left(1^{\circ}\right.$ Semestre, 2006): 27-46. fiados eran enviados para su publicación.

2. En el caso de este texto, se puede comprobar el siguiente procedimiento:

a. El texto escrito a mano por Elena de White aparece escrito así en inglés: "There are (the) living three persons (alities) of the heavenly trio...". Traducido al español sería "Existen tres personalidades del trío celestial".

b. El texto dactilografiado y revisado por Elena de White dice "There are three living persons of the heavenly trio...". De modo que el cambio de personalidades (personalities) a personas (persons) ocurrió en esta etapa. Sin embargo, en esta etapa el texto fue revisado y aprobado para su publicación por la pro- 
pia Elena de White, esto quiere decir que ella estaba plenamente consciente del cambio y permitió su publicación.

c. Cuando el texto fue publicado en el año 1906 decía: "There are three living persons of the heavenly trio...", es decir exactamente como estaba en el texto dactilografiado por la secretaria y revisado por Elena de White.

d. Otro detalle importante es que el libro que contiene este texto fue publicado en 1906 con el título "Testemonies for the church", y en su primera página aparece la frase PU. BLISHED FOR THE AUTOR, que significa "publicado por la autora". Es decir, fue la propia Elena de White que supervisó el proceso de publicación de esta obra.
3. En conclusión:

a. Sí hay una diferencia entre el manuscrito (personalidades) y lo que finalmente se publicó (personas).

b. Sin embargo, no hay duda que Elena de White conoció y aprobó el cambio de texto de personalidades a personas.

c. No hay duda que este texto fue publicado cuando Elena de White estaba viva y podía rechazar esa edición. Ella nunca lo hizo.

d. No existe un solo indicio que el texto haya sido cambiado por algunos líderes de la Iglesia.

\section{Mis razones para haber participado de este debate}

Comprendo plenamente la posición según la cual es necesario evitar al máximo el debatir en torno a las verdades bíblicas, 
pues creo que la Biblia no está para ser debatida sino para ser vivida. Debido a esto explicaré las razones por las cuales participé en un debate de esta naturaleza. Voy a tomar casi literalmente las palabras que le dirigí a mi propio interlocutor cuando debatíamos sobre este tema.

\section{Aprecio personal por mi} interlocutor. La persona que me llevó a contactarme con la web Arquivos $X$ da IASD, fue uno de los líderes con mayor espíritu misionero de una de mis iglesias. Fueron muchas las oportunidades que visité su hogar y a su familia. La noticia de su incredulidad con respecto a una de las doctrinas básicas de nuestra Iglesia causaron profunda tristeza en mí y en mi esposa. Lamentablemente estábamos saliendo de ese distrito misionero y fue muy poco lo que pudimos hacer por él. Cuando recibí su email, creí ver una oportunidad para ayudar a mi querido hermano Samuel, y así propiciar su completo retorno a las filas de la Iglesia remanente.

2. Aprecio por mis hermanos de iglesia. Por testimonio del propio Samuel, sabía que había un grupo de hermanos de iglesia que estaban siguiendo nuestro debate. Los emails eran reenviados para otros hermanos. No sé exactamente quiénes siguieron atentamente el debate, pero no quería dar la impresión que la Iglesia no tiene respuesta a las múltiples alegaciones de los antitrinitarios. Sabiendo que la doctrina de nuestra Iglesia es plenamente bíblica, me aferré a la Sagrada Escritura, y salí a enfrentar las argumentaciones que me presentaban. Si un solo hermano ha visto fortalecida su fe, o ha encontrado argumentos para rebatir la 
disidencia, entonces valió la pena participar de este agotador intercambio de emails con Samuel.

3. Defensa de la verdad. Siendo que, como todo adventista, fui bautizado en el nombre del Padre, del Hijo y del Espíritu Santo; no puedo quedar neutral cuando soy testigo de un tremendo ataque a la verdad, y creo que ningún cristiano debe tener temor en posicionarse en defensa de las verdades bíblicas. Es verdad que debemos evitar los debates estériles, pero también es cierto que, cuando la ocasión lo exija, debemos estar preparados para hacer una firme y bien fundamentada defensa de nuestra fe.

4. Defensa de la Iglesia. Vivimos tiempos solemnes y peligrosos. Somos la última generación de hijos de Dios, el remanente fiel que se mantendrá hasta la culminación de la his- toria de este mundo. No tengo dudas que el enemigo quiere destruir a la Iglesia verdadera, y usará todo su maléfico arsenal para lograr su propósito. La Iglesia no es perfecta, pero es el cuerpo de Cristo y triunfará gloriosamente. He visto el surgimiento de muchos movimientos disidentes, $\mathrm{y}$ estos continuarán surgiendo hasta el fin del tiempo, sin embargo, la Palabra de Dios nos muestra un cuadro del triunfo seguro e inexorable contra las fuerzas del diablo.

\section{Preguntas que los antitrinitarios no respondieron}

Finalmente, me gustaría dejar algunas preguntas que podrían ser útiles al debatir con quienes se aferran a las ideas antitrinitarias, como las que se presentan en Arquivos $X d a$ IASD. 
1. ¿Por qué es aceptable la frase "Su representante, el Espíritu Santo" en la declaración publicada en los Yearbooks, y no es aceptable la frase "representante" en el Deseado de todas las gentes?

2. En su concepción ¿El Hijo es eterno o existió solo después de ser creado por el Padre? ¿El Hijo es Dios? ¿El Hijo es una persona diferente del $\mathrm{Pa}$ dre? ¿El Padre y el Hijo son dos personas y un solo Dios?

3. Usted acepta la declaración de Uriah Smith en 1865 donde asegura que Cristo fue el primer ser creado, o acepta el rechazo que hace de esta idea en 1898.

4. Uriah Smith rechazó inicialmente la justificación por la fe tal como fue presentada por los hermanos Jones y Waggoner ¿También habrían sido este el motivo de las declaraciones elogiosas que
Elena de White hace sobre él?

5. El hecho que Elena de White dijese palabras elogiosas sobre Martín Lutero ¿Significa que no deberíamos guardar el sábado como él?

6. ¿Debemos ahora aceptar la posición de Jaime White, que, en 1852, desde su postura antitrinitaria escribió: "Aseverar que las afirmaciones del Hijo y sus apóstoles son mandamientos del Padre está tan distante de la verdad como el viejo absurdo trinitario de que Jesucristo es el verdadero y eterno Dios"?

7. En 1892, la Pacific Press, donde Waggoner ejercía la función de editor, publicó el trabajo de un no adventista sobre la Trinidad, con el título The Bible doctrine of the Trinity (La doctrina bíblica de la Trinidad). Elena de White en otras oportunidades censuró a la Review 
and Herald y a la propia Pacific Press, cuando en ellas aparecían posiciones que contradecían las doctrinas adventistas, pero este artículo nunca fue censurado. ¿Por qué Elena de White jamás censuró a la Pacific Press por haber publicado este artículo donde se defendía abiertamente la supuesta herejía de la Trinidad?

8. ¿Cómo el Espíritu Santo podría ser parte del trío celeste -tal como lo llama Elena de White-si no tiene la misma esencia del Padre y del Hijo?

\section{Conclusiones}

Después de haber participado de esta inusual experiencia -la llamo inusual porque hasta ahora ha sido la única vez que he participado en un debate con estas características- me gustaría colocar algunas conclusiones:

1. El internet ofrece un es- pacio que ha sido y seguirá siendo usado para atacar a la Iglesia adventista, su organización y sus doctrinas. Esto significa que muchos jóvenes o adultos pueden fácilmente tener acceso a páginas como Arquivos $X$ da IASD, que contienen ataques contra la Iglesia Adventista del $7^{\circ}$ Día. Muchas de estas personas pueden verse seducidas por el aura de misterio que crean estos autores, creo que es necesario hacerles saber que la Iglesia tiene respuestas contundentes a cada una de las falsas alegaciones de la disidencia antitrinitaria.

2. No creo que sea necesario responder a cada una de las acusaciones que se levanten en Internet contra la Iglesia. Tampoco soy tan ingenuo como para pensar que sea posible hacerlo. Sin embargo, sí es necesario crear una corriente de pleno escep- 
ticismo entre los miembros de Iglesia respecto a las informaciones vertidas en internet. Es bueno que la feligresía sea prevenida respecto de la identificación de fuentes confiables y cómo usarlas.

3. Los ataques que enfrenta la Iglesia en internet, muchas veces son construidos con la presentación de abundantes detalles históricos y acompañados de fotos y facsímiles que pueden darles cierta apariencia de seriedad y exactitud. Sin embargo, hay que estar atentos a los aspectos principales de la discusión. Por ejemplo, en Arquivos $\chi$ da IASD se presenta con cierta minuciosidad las pruebas de las creencias antitrinitarias de ciertos pioneros, pero no se ocupan del tema principal, que la única norma de fe y doctrina que tenemos como adventistas es la Biblia.
4. Como adventistas, tenemos un firme fundamento doctrinal y un rico acervo teológico. Sin embargo, toda esta bendición no nos servirá de mucho si somos analfabetos funcionales en la teología bíblica adventista. Es necesario que cada miembro de Iglesia cada día sea motivado a crecer en el conocimiento de la Palabra de Dios, y en los escritos de Elena G. de White.

5. No recomiendo entrar en debates teológicos de este tipo, a menos que sea absolutamente inevitable, y en esos casos, debemos tener la humildad suficiente para desdeñar nuestros razonamientos y dejarnos conducir por la suave voz del Espíritu Santo. Y el Espíritu es paz y no contienda, es gozo y no ira, es amor y no orgullo, es humildad y no presunción. 


\section{Bibliografía}

Whidden, Woodrow, Ellen White on the Humanity of Christ. Hagerstown, MD: Review and Herald, 1997.

Whidden, Woodrow, Jerry Moon y John W. Reeve. La trinidad. 1ra ed. Tranducido por David P. Gullón. Buenos Aires: Asociación Casa Editora Sudamericana, 2007.

White, Elena G. de. Testimonios selectos. 5 vols. Buenos Aires: Casa Editora Sudamericana, 1942. Primeros escritos. Mountain View, CA: Pacific Press Publishing Association, 1962.
Mensajes selectos. 3 vols. Mountain View, CA: Pacific Press Publishing Association, 1966.

Alza tus ojos. Buenos Aires: Asociación Casa Editora Sudamericana, 1988.

. El evangelismo. Buenos Aires: Casa Editora Sudamericana, 1991. . El conflicto de los siglos. Bogotá: Asociacion Publicadora Interamericana, 2007.

White, James R. The Forgotten Trinity. Minneapolis, MN: Bethany House Publishers, 1998. 